\title{
Pharmacists' practices and challenges regarding Continuing Professional Development in Mpumalanga province, South Africa
}

\author{
Lisbeth Cathrine Gumede, Elvera Helberg, Selente Bezuidenhout \\ School of Pharmacy, Sefako Makgatho Health Sciences University, Ga-Rankuwa, South Africa
}

Keywords
Continuing education
Continuing professional development
CPD online recording system
Pharmacy education
South African Pharmacy Council
Correspondence
Lisbeth Gumede
School of Pharmacy
Sefako Makgatho Health Sciences University
lisbethgumede@gmail.com

lisbethgumede@gmail.com

\begin{abstract}
Introduction: The study aimed to assess the extent to which pharmacists in Mpumalanga Province, South Africa, voluntarily participated in recording their CPD activities on the CPD online recording system of the South African Pharmacy Council (SAPC), and to identify associated challenges. Methods: A quantitative, descriptive study was conducted. Data were collected using Survey Monkey from 578 registered pharmacists over a four month period. Responses were exported to Microsoft Excel and analysed using SPSS version 25. Results: The response rate was $25.4 \%$. Most pharmacists (87\%) agreed that CPD was necessary. While $64 \%$ participated in CPD activities, only $24.8 \%$ recorded these activities voluntarily. Challenges faced with participating in recording activities included recording of CPDs is currently not mandatory (27.3\%), lack of information (27.3\%), lack of interest (27.3\%), time constraints (39.1\%) and system/programme issues (26.1\%) were also cited as reasons for not recording CPD activities. Conclusion: Improving the ease of accessing the SAPC system (83.7\%) was suggested as a way to improve participation in CPD activities and subsequent recording online.
\end{abstract}

\section{Introduction}

"Pharmacists are health care professionals whose professional responsibilities include seeking to ensure that people derive maximum therapeutic benefit from their treatments with medicines. This requires them to keep abreast of developments in pharmacy practice and the pharmaceutical sciences, professional standards requirements, the laws governing pharmacy and medicines and advances in knowledge and technology relating to use of medicines" (FIP policy statement, 2002: p. 7). Recommendations by the International Pharmaceutical Federation (FIP) states that pharmacists are required to continuously update their skills to ensure quality patient care. The evolving professional role of pharmacists mandates them to adapt to deliver quality, evidence-based and patientcentred care (Gelayee, Mekonnen \& Birarra, 2018). In this process, it is imperative that individuals be able to develop their learning needs and plan accordingly to address them (Rouse, 2004). Continuing Professional Development (CPD) facilitates the ongoing acquisition
\end{abstract}

of knowledge and skills pertinent for pharmacists to stay up to date and competent in practice which ultimately benefits the patients (Kenya Pharmacy and Poisons Board, 2013).

Evolving population demographics and disease patterns, in addition to progression in technology, diagnostics and treatment methods, have necessitated the need for health professionals to progressively advance their knowledge and skills (Geyalee et al., 2018; Wheeler \& Chisholm-Burns, 2018). The pharmacy profession is continually adapting to provide safe and patient-centred health services, and this requires pharmacists to ensure continued competence in practice (Wheeler \& Chisholm-Burns, 2018). Implementation of continuing professional development (CPD) systems is necessary to address performance gaps and facilitate quality improvement in the health sector (Geyalee et al., 2018; Wheeler \& ChisholmBurns, 2018). 
The global CPD models have evolved over time. Continuing Professional Development is a concept developed in the early 2000's from an older concept of Continuing Education (CE). The FIP (2014) defined CPD as "the responsibility of individual pharmacists for systematic maintenance, development and broadening of knowledge, skills and attitudes, to ensure continuing competence as a professional, throughout their careers" (FIP, 2014: p. 2). Whereas the Accreditation Council for Pharmacy Education (ACPE) (2015) in Chicago, United States of America (USA) defined CE as "structured educational/activity designed or intended to support the continuing development of pharmacists and/or pharmacy technicians to maintain and enhance their competence" (Owen, Skelton \& Maine, 2020: p. 1). The South African Pharmacy Council (SAPC) defines CPD as "a process by which registered persons maintain and enhance their competence throughout their professional careers" (SAPC, 2019: p. 3).

Globally, pharmacists have different perceptions and practices regarding CPD. A study on pharmacist's knowledge and attitude in Texas, USA, in 2008, showed that almost $50 \%$ of the pharmacists who participated in their study had not heard of the CPD model prior to the review and more than $50 \%$ of those pharmacists were uncertain of the profits of the system (Bellanger \& Shank, 2010). In Botswana, a study among pharmacists in 2014 showed that most did not feel that recording their CPD had any significant contribution to their practice (Kasvosve et al., 2014). Another study in Scotland revealed that when comparing community pharmacists with hospital and primary care pharmacists, community pharmacists participated the least in CPD activities (Power et al., 2008). To ensure lifelong learning, the Pharmacy Board of Australia made CPD mandatory in 2015 to maintain registration (Pharmacy Board of Australia, 2015). In 2013, an online survey was conducted to investigate the level of understanding by Australian pharmacists of the CPD framework. The results of the Australian study showed that most pharmacists (85.4\%) knew the CPD requirements for registration and also agreed that they received sufficient guidance for CPD requirements. However, a minority (10.7\%) did not know the difference between CPD and CE and were not fully aware of the significance of the four steps in the CPD learning cycle (Thompson \& Nissen, 2013). While this study was conducted, only intern pharmacists and tutors had to submit CPD activities. All CPD recordings for other registered pharmacists were voluntary. However, the regulations relating to CPD made in terms of Section 33 (1) (0) of the Pharmacy Act, 1974 (Act no. 53 of 1974) was published in the government gazette on 17 May 2019. This then made provision that the SAPC, may from time to time, specify by a Board Notice which categories of persons registered in terms of
Section 14 of the Pharmacy Act are required to record their CPD activities (Pharmacy Act, 1974). On the first of February 2020, the SAPC launched a new CPD page. All pharmacists' were then required to submit their annual declaration by the first of May 2020 and a minimum of six CPD entries by 31 December 2020. This study sought to determine the extent to which pharmacists voluntarily participate in the online recording of CPD activities and the barriers that prevent the recording of CPD activities in the Mpumalanga Province, South Africa.

\section{Methods \\ Participants}

A quantitative study was conducted using a descriptive approach. The study included all 636 actively registered pharmacists and specialist pharmacists with the SAPC practising within the Mpumalanga Province in South Africa in all sectors of pharmacy at the time of the study. However, only 616 pharmacists provided the SAPC with their email addresses, of which 38 were inactive. The actual sample therefore comprised of 578 pharmacists. A pilot study was conducted on 13 pharmacists; their responses were analysed and used to improve the questionnaire's validity and reliability.

\section{Ethical considerations}

Ethical approval was obtained from the Sefako Makgatho Health Sciences University Research and Ethics Committee (SMUREC/P/176/2017:PG). The cover letter on the emails stated that participation was voluntary and that withdrawal was possible at any stage. Participation in the research was regarded as consent to the study.

\section{Instrument}

A structured online questionnaire comprising of two sections was developed by the researcher after the literature review. It was loaded onto Survey Monkey. Section 1 focused on the demographic information of the participants, whereas section 2 focused on information relating to participation in and recording of CPDs. Open and close-ended questions covered the understanding of the term CPD, knowledge of and ease of access of the CPD online recording system, participation in CPD and subsequent recording of CPD activities, barriers to participation and recording, the types of CPD activities, professional association membership and suggestions to improve CPD were also part of the questionnaire. Results from the pilot study were used to limit confusion and create a flow of 
questions. Respondents were not required to answer all questions in order to submit the questionnaire.

\section{Procedure}

The structured questionnaire was uploaded onto Survey Monkey. The survey cover letter and the link of the survey were then emailed to the 578 pharmacists. Data were collected over a period of 14 weeks. Reminder emails were sent every second Wednesday, totalling seven reminders over the data collection period. The online structured questionnaire was completed anonymously by the participating pharmacists.

\section{Data analysis}

The collected data were kept within SurveyMonkey and were accessible through login details. At the end of the data collection period, data from SurveyMonkey were exported to Microsoft Excel, arranged, coded and discussed with the statistician. Categories were created for open-ended questions. Data analysis was carried out at a 95\% confidence interval, using the Statistical Package for the Social Sciences (SPSS) version 25. Descriptive statistics, frequencies and percentages were used to summarise data. The summarised data were then classified according to the research objectives.

\section{Results}

Of the 578 pharmacists that met the selection criteria, only 147 pharmacists responded to the structured questionnaire, giving a response rate of $25.43 \%$.

The response rate $(25.43 \%)$ from this study corroborates with response rates recorded in similar studies conducted among pharmacists in Malaysia (31\% and 29.2\%) (Aziz et al., 2013). An even lower response rate $(9.5 \%)$ was reported for a web-based survey conducted among pharmacists in Texas, USA. Electronic studies have been reported to yield lower response rates compared to paper-based surveys (Bellanger \& Shank, 2010).

\section{Demographic characteristics}

The demographic characteristics of the pharmacists are presented in Table I. More females (53.6\%) participated in the study. Pharmacists (26.5\%) who participated in the study were mainly aged between 25 and 30 years. Pharmacists working in the private sector (63.6\%) participated more than those from the public sector, with $57.0 \%$ of these pharmacists $(63.6 \%)$ working in community pharmacies. More than half of the pharmacists (58.9\%) registered for practice within the last decade. Approximately a third of pharmacists (39\%) had practised for less than five years. Only $7 \%$ of the pharmacists had a Master's degree. Four pharmacists obtained their qualifications outside South Africa, and most pharmacists (83.5\%) were active members of the Pharmaceutical Society of South Africa (PSSA).

The gender distribution ( $53.6 \%$ female $\& 46.4 \%$ male) is consistent with SAPC records which show that there are currently more registered female pharmacists (9421) than males (5650) (South African Pharmacy Council, 2018). However, a study conducted on CPD in Texas by Bellanger \& Shankin (2008) found that there were more male participants $(54.1 \%)$ who completed their survey.

In the Mpumalanga Province, there are 273 registered community pharmacies, 66 institutional pharmacies, one manufacturing pharmacy and three private wholesale pharmacies (South African Pharmacy Council, 2018), which would explain why most participating pharmacists $\mathbf{( 5 7 . 0 \% )}$ were from community pharmacies.

Although the majority of pharmacists $(86.39 \%)$ were members of one or more professional associations, only $24 \%$ of pharmacists attended CPD activities organised by these associations. Professional association membership is advantageous as such associations often facilitate several CPD workshops for pharmacists who can attend for free or at a minimal fee. These workshops can be used to augment practice skills for career strengthening and advanced patient care (Moyo \& Renard, 2016). Professional associations can potentially develop and coordinate CPD strategies and create incentives for professionals at various levels of performance to improve service delivery (Moyo \& Renard, 2016).

\section{Pharmacist participation in CPD}

A collective of $86.6 \%$ of pharmacists agreed that CPD was necessary, with $28.4 \%$ of pharmacists ( $n=141$ ) strongly agreeing that a CPD programme was necessary for the profession and $58.2 \%$ of pharmacists agreeing on its necessity.

More than $60 \%$ of pharmacists had participated in CPD activities, with $84.7 \%$ of these pharmacists attending CPD activities in the last two years. Most pharmacists (73.6\%) participated in at least four CPD activities annually. Only $7.8 \%$ of pharmacists cited reasons for not participating in CPD activities which included CPD not being mandatory $(27.3 \%)$, a lack of information on the CPD process $(27.3 \%)$, lack of interest in participating in CPD's (27.3\%) and lack of time for participating in CPD's (18.2\%). 
Table I: Pharmacist's demographic characteristics

\begin{tabular}{|c|c|c|}
\hline Variable (n) & & $\begin{array}{c}\text { Frequency, } \\
n(\%)\end{array}$ \\
\hline \multirow[t]{2}{*}{ Gender (138) } & Female & $74(53.6)$ \\
\hline & Male & $64(46.4)$ \\
\hline \multirow{6}{*}{$\begin{array}{l}\text { Age (years) } \\
(147)\end{array}$} & $20-25$ & $16(10.9)$ \\
\hline & $>25-30$ & $39(26.5)$ \\
\hline & $>30-35$ & $27(18.4)$ \\
\hline & $>35-40$ & $23(15.7)$ \\
\hline & $>40-50$ & $18(12.2)$ \\
\hline & $>50$ & $24(16.3)$ \\
\hline \multirow{2}{*}{$\begin{array}{l}\text { Sector of } \\
\text { practice }(140)\end{array}$} & Private & $89(63.6)$ \\
\hline & Public & $51(34.4)$ \\
\hline \multirow{12}{*}{$\begin{array}{l}\text { Area of } \\
\text { practice (142) }\end{array}$} & Community pharmacy & $81(57.0)$ \\
\hline & Institutional pharmacy & $41(28.9)$ \\
\hline & Primary Health Care clinic & $6(4.2)$ \\
\hline & Wholesale pharmacy & $4(2.8)$ \\
\hline & Non-governmental organisation & $3(2.1)$ \\
\hline & Manufacturing pharmacy & $2(1.4)$ \\
\hline & Medical aid- Drug Utilisation & $1(0.7)$ \\
\hline & Review & \\
\hline & Management & $1(0.7)$ \\
\hline & Pharmaceutical depot & $1(0.7)$ \\
\hline & Pharmaceutical industry & $1(0.7)$ \\
\hline & Occupational health care & $1(0.7)$ \\
\hline \multirow{6}{*}{$\begin{array}{l}\text { Highest } \\
\text { qualification } \\
\text { obtained (141) }\end{array}$} & B.Pharm & $121(85.8)$ \\
\hline & Master's degree & $10(7.1)$ \\
\hline & Dip Pharm & $4(2.8)$ \\
\hline & Honours degree & $2(1.4)$ \\
\hline & BSc Dip Pharm & $2(1.4)$ \\
\hline & $\begin{array}{l}\text { Primary Care Drug Therapy } \\
\text { (PCDT) }\end{array}$ & $1(0.7)$ \\
\hline \multirow{5}{*}{$\begin{array}{l}\text { Years of } \\
\text { practice as a } \\
\text { pharmacist } \\
(142)\end{array}$} & $\leq 5$ & $55(38.7)$ \\
\hline & $>5-10$ & $33(23.2)$ \\
\hline & $>10-15$ & $17(12.0)$ \\
\hline & $>15-20$ & $9(6.3)$ \\
\hline & $>20$ & $28(19.7)$ \\
\hline \multirow{5}{*}{$\begin{array}{l}\text { Years of } \\
\text { registration as } \\
\text { a pharmacist } \\
(134)\end{array}$} & $2009-2018$ & 79 (58.9) \\
\hline & 1999-2008 & $25(18.7)$ \\
\hline & 1989-1998 & $11(8.2)$ \\
\hline & $1979-1988$ & $12(8.9)$ \\
\hline & 1969- 1978 & $7(5.2)$ \\
\hline
\end{tabular}

Encouragingly, $84.5 \%$ of the pharmacists displayed understanding and could correctly explain the CPD concept. This result is higher than results reported in an Ethiopian survey, where more than half of the pharmacists did not understand the concept (Gelayee et al., 2018). Similarly, it was also reported that pharmacists in developing countries only became aware of the CPD concept after an intervention such as training (Adepu \& Shariff, 2010).

Globally, health professional boards are progressively requiring registered professionals to engage in CPD to maintain high competence standards (Kasvosve et al., 2014). Most respondents (86.5\%) agreed that CPD activities were necessary. This is consistent with other study findings observed among pharmacists in Kenya and Malaysia (Aziz et al., 2013; Kenya Pharmacy \& Poisons Board, 2013). 93\% of pharmacists agreed that CPD systems assisted them in staying conversant with the latest pharmaceutical developments. This is important for providing quality pharmaceutical care services and ensuring patient safety in practice (Tran et al., 2014).

\begin{tabular}{llc}
\hline Variable (n) & Frequency, \\
& $\mathbf{n}(\%)$
\end{tabular}

Despite agreeing that CPD was important, only $63.8 \%$ had previously participated in CPD activities. These findings were lower than those reported in a Kenyan study by pharmacists and pharmaceutical technologists, where $85.6 \%$ had participated in CPD activities (Kenya Pharmacy \& Poisons Board, 2013). Discouragingly, only 53 pharmacists $(36 \%)$, had participated in at least four CPD activities per year. Pharmacists' attitude and perceptions towards CPD needs to be urgently addressed as some stated that they did not perceive any value in CPD.

The most common CPD activities that the pharmacists reported that they engaged in were attending pharmaceutical companies training events and reading journals. These were also reported as the most common CPD activities in studies conducted among pharmacists in Kenya and Malaysia (Aziz, Jet \& Rahman, 2013; Kenya Pharmacy and Poisons Board, 2013).

\section{The SAPC online CPD recording system and associated challenges}

Table II presents information on the registration status of pharmacists on the SAPC online CPD recording system as well as the reasons for not having a password to access the SAPC CPD online recording system. 
Table II: Access to the SAPC online CPD recording system

\begin{tabular}{|c|c|}
\hline $\begin{array}{l}\text { Access to SAPC online CPD recording } \\
\text { system }\end{array}$ & Frequency, $n(\%)$ \\
\hline \multicolumn{2}{|c|}{$\begin{array}{l}\text { Pharmacist registered on the SAPC website to access online } \\
\text { CPD recording system ( } n=139)\end{array}$} \\
\hline Yes & $91(65.5)$ \\
\hline No & $48(34.5)$ \\
\hline \multicolumn{2}{|c|}{$\begin{array}{l}\text { Online registration to obtain a login password considered } \\
\text { easy }(n=113)\end{array}$} \\
\hline Yes & $70(61.9)$ \\
\hline No & $43(38.1)$ \\
\hline \multicolumn{2}{|c|}{$\begin{array}{l}\text { Challenges experienced during online registration to obtain } \\
\text { a login password }(n=16)\end{array}$} \\
\hline SAPC website not user-friendly & $12(75.0)$ \\
\hline Too time-consuming & $2(12$ \\
\hline Never tried & $2(12.5)$ \\
\hline \multicolumn{2}{|c|}{$\begin{array}{l}\text { Reasons for not having a password to access the SAPCCPD } \\
\text { online recording system }(n=18)\end{array}$} \\
\hline Have no interest in having one & $10(55.6)$ \\
\hline tion on how to get one & $5(27.8)$ \\
\hline uming to get one & $2(11.1)$ \\
\hline $\begin{array}{l}\text { Lack of support from SAPC in the } \\
\text { acquiring process }\end{array}$ & $1(2.6)$ \\
\hline \multicolumn{2}{|c|}{ Willingness to obtain login password $(n=48)$} \\
\hline Yes & $18(37.5)$ \\
\hline No & $30(61.5)$ \\
\hline \multicolumn{2}{|c|}{$\begin{array}{l}\text { Reasons for not planning on obtaining a login password } \\
(n=5)\end{array}$} \\
\hline Don't know how to use the website & $1(20.0)$ \\
\hline Do not think CPD is necessary & $1(20.0)$ \\
\hline $\begin{array}{l}\text { It is very difficult and lots of } \\
\text { information needed to complete this } \\
\text { online - very unnecessary }\end{array}$ & $1(20.0)$ \\
\hline $\begin{array}{l}\text { Time-consuming, family time after } \\
\text { hours important. }\end{array}$ & $1(20.0)$ \\
\hline Planning to retire from the profession & $1(20.0)$ \\
\hline \multicolumn{2}{|c|}{$\begin{array}{l}\text { Challenges experienced during online registration to obtain } \\
\text { a login password }(n=16)\end{array}$} \\
\hline $\begin{array}{l}\text { SAPC website is said to not be user- } \\
\text { friendly }\end{array}$ & $12(75.0)$ \\
\hline
\end{tabular}

$65 \%$ per cent of pharmacists had access to the SAPC online CPD recording system, and $61.9 \%$ found the registration process easy. Also, some pharmacists said they did not know how to use the online system.

Only $32 \%$ of pharmacists completed the online annual declaration in the previous two years, as depicted in Table III. The majority of pharmacists (75.2\%) did not record their participation in CPD activities, citing the following reasons: a lack of time (39.1\%) and $64.8 \%$ of the pharmacists' reported programme/system issues.

Almost $40 \%$ of pharmacists had completed the online annual declaration in the previous two years. More than $60 \%$ of pharmacists had participated in CPD activities, with most of the activities (84.7\%) being in the last two years. The majority of pharmacists (73.6\%) have taken part in at least four CPD activities annually. Reading journals (39.2\%) is the most common CPD activity.
Table III: Recording of CPD activities on the SAPC online CPD recording system and associated challenges

\begin{tabular}{|c|c|}
\hline $\begin{array}{l}\text { Recording of CPD activities by } \\
\text { pharmacists }\end{array}$ & Frequency, $\mathrm{n}(\%)$ \\
\hline \multicolumn{2}{|c|}{$\begin{array}{l}\text { Completion of the annual declaration on the SAPC system } \\
(n=141)\end{array}$} \\
\hline Yes & $46(32.6)$ \\
\hline No & $95(67.4)$ \\
\hline \multicolumn{2}{|c|}{ Previous recording of any CPD activities ( $n=125$ ) } \\
\hline Yes & $31(24.8)$ \\
\hline No & $94(75.2)$ \\
\hline \multicolumn{2}{|c|}{ Reasons for not recording CPD activities ( $n=46$ ) } \\
\hline Lack of time & $18(39.1)$ \\
\hline System/program issues & $12(26.1)$ \\
\hline Lack of interest & $11(23.9)$ \\
\hline Lack of information & $5(10.1)$ \\
\hline \multicolumn{2}{|c|}{ Recording of CPD activities considered easy ( $n=71)$} \\
\hline Yes & $25(35.2)$ \\
\hline No & $46(64.8)$ \\
\hline \multicolumn{2}{|c|}{ Challenges faced when recording CPD activities online ( $n=25)$} \\
\hline System/program issues & $18(72.0)$ \\
\hline Lack of time & $7(28.0)$ \\
\hline
\end{tabular}

The main reasons for not recording CPDs were time constraints and that both participating and recording were not yet compulsory at the time the study was conducted. These factors were similar to those found in studies conducted among pharmacists in Australia and Lebanon (Tran et al., 2014; Saade et al., 2018). The infrequent recording of CPD activities was also attributed to difficulties in accessing the CPD online system as $38 \%$ remarked it had not been easy for them to obtain login credentials on the SAPC website. Challenges with online access were also reported among pharmacists in the UK (Donyai et al., 2011). In this study, almost $35 \%$ of the pharmacists had not registered on the website and could therefore not record CPD activities. In this era of technological advancement, it is vital that pharmacists be technology literate and acquaint themselves with computer skills as these are required when offering patient services (Grappasonni et al., 2014). It is important to record CPD activities to evaluate, and document achieved outcomes (Tran et al., 2014). Documenting these activities serves as evidence that the pharmacist is committed to self-development and is competent to deliver quality services to patients (Tran et al., 2014).

Unlike other countries such as New Zealand and Australia, where participation in CPD activities are mandatory, this was not the case in South Africa (SA) at the time of this study. This played a significant role in suboptimal participation and CPD recording by registered pharmacists in the Mpumalanga Province. In this study less than five percent of pharmacists agreed to making CPD mandatory for all pharmacists as similarly reported in another study conducted in Australia (Tran et al., 2014). In another study carried 
out in Ethiopia, $85 \%$ of the respondents suggested that CPD should be mandatory for pharmacists (Gelayee et al., 2018).

\section{Barriers to participating in CPD}

Table IV provides information on the barriers faced with attending and recording CPD activities sponsored by professional associations and also information on pharmacists' recording of CPD activities on the SAPC online CPD recording system.

Table IV: Participation in and recording of CPD activities sponsored by professional associations

\begin{tabular}{|c|c|}
\hline & Frequency, n (\%) \\
\hline \multicolumn{2}{|c|}{$\begin{array}{l}\text { Attendance of conferences hosted by professional associations } \\
(n=129)\end{array}$} \\
\hline Yes & $31(24.0)$ \\
\hline No & $98(75.9)$ \\
\hline \multicolumn{2}{|c|}{$\begin{array}{l}\text { Online recording of conferences hosted by professional } \\
\text { associations as CPD activities ( } n=80)\end{array}$} \\
\hline Yes & $5(6.3)$ \\
\hline No & $75(93.7)$ \\
\hline \multicolumn{2}{|c|}{$\begin{array}{l}\text { Barriers faced with recording conference attendance as CPD } \\
\text { activity }(n=26)\end{array}$} \\
\hline Lack of information & $4(15.4)$ \\
\hline Time-consuming & $16(61.5)$ \\
\hline Too costly to record & $1(3.9)$ \\
\hline Recording is not mandatory & $5(19.2)$ \\
\hline \multicolumn{2}{|c|}{$\begin{array}{l}\text { Attendance of CPD workshops offered by professional } \\
\text { associations ( } n=132)\end{array}$} \\
\hline Yes & $49(37.1)$ \\
\hline No & 83 (62.9) \\
\hline \multicolumn{2}{|c|}{$\begin{array}{l}\text { Online recording of professional association sponsored } \\
\text { workshops as CPD activities ( } n=89)\end{array}$} \\
\hline Yes & $8(9.0)$ \\
\hline No & $81(91.0)$ \\
\hline \multicolumn{2}{|c|}{$\begin{array}{l}\text { Reasons for not recording professional association sponsored } \\
\text { workshops as CPD activities ( } n=31 \text { ) }\end{array}$} \\
\hline Time-consuming & $13(41.3)$ \\
\hline Recording not compulsory & $7(22.6)$ \\
\hline Lack of information & $6(19.4)$ \\
\hline $\begin{array}{l}\text { Difficulties experienced with the } \\
\text { recording system }\end{array}$ & $5(16.1)$ \\
\hline
\end{tabular}

Pharmacists (98.6\%) listed the following barriers for not participating in CPD activities: time constraints (87.1\%), family and social commitment (38.8\%), misperceptions and misunderstanding on the importance of CPD (20.9\%), difficulty complying with objectives and outcomes as stipulated by the SAPC (17.1\%), employer's restrictions on what employees can partake in during working hours (15.6\%) and difficulty in identifying possible learning needs (8.2\%).

Only $24.8 \%$ of pharmacists had previously recorded CPD activities on the SAPC online CPD recording system. Of the pharmacists $(24.0 \%)$ who previously had attended conferences hosted by professional associations, only $6.3 \%$ recorded this as a CPD activity.
Pharmacists (98.6\%) suggested that increased access to information on CPD as a whole (59.7\%), improved ease in the recording system $(30.9 \%)$, making it mandatory (5.8\%) and making them realise the need (3.6\%) could possibly improve participation and recording of CPD activities. Regrettably, some pharmacists $(10.8 \%)$ even felt that there is no need for recording CPD activities.

Other studies highlighted similar challenges to CPD participation as cited in this study, such as lack of awareness about CPD activities, inaccessibility, time constraints, lack of relevant activities and work commitments (Marriott, Duncan \& Namara, 2007; Kenya Pharmacy and Poisons Board, 2013; Gelayee et al. 2018). When CPD activities are relevant for the pharmacist, motivation to participate may be increased (Laaksonen, Duggan \& Bates, 2009; Saade et al., 2018). In this study, there were additional challenges like misperception and misunderstanding of CPD's and the fact that CPD's are not mandatory. A study conducted in the USA during 2008, amongst pharmacists, also cited being too old to learn new things and the perception that one was too experienced to learn as reasons for non-participation by pharmacists (Laaksonen et al., 2009).

\section{Limitations}

The study was conducted in only one province in South Africa. Hence the results may not be accurately representative of pharmacists in other provinces in South Africa. The researchers acknowledge that the low response rate further limits the generalisability of the findings in this study. Another limitation was most responses were from the community and institutional pharmacists, therefore potentially raising questions about the representativeness of the findings regarding other pharmaceutical sectors. Self-reporting of CPD participation may have potentially resulted in exaggerated findings. Despite these limitations, the researchers believe the findings are robust and provide relevant information for future CPD related decisions and actions by various stakeholders.

\section{Conclusions}

This paper presented an assessment of the extent to which pharmacists in the Mpumalanga Province voluntarily participated in recording CPD activities on the SAPC'S online recording system. The study found that participation in and recording of CPD activities is not optimal in Mpumalanga. Barriers to recording were lack of interest, time constraints, lack of adequate information and challenges with the SAPC online 
system. This negatively impacts pharmacists' lifelong learning and professional development. Gaps in the implementation of CPDs should be addressed to successfully align with the diverse and growing needs of the South African health care system. Now that South Africa has made CPD mandatory, a new study can be conducted to study the new recording rate and the pharmacist's perceptions.

In order to record, pharmacists must first participate in CPD activities, which is why issues affecting participation must be addressed. An increase in interest in CPD might encourage people to create more time to participate and therefore record. Further investigation into strategies that can create a positive attitude whilst improving CPD participation, other than making it mandatory, is needed in South Africa. Professional competence contributes to overall patient outcomes. Because $27.3 \%$ of the pharmacists stated that they lack an interest in participation in CPD, with $17.1 \%$ having difficulties identifying objectives and $8.2 \%$ having challenges with choosing a learning need, it is therefore recommended that the SAPC creates a platform to make suggestions on the nature of topics/subject areas that can be addressed at CPD meetings. This will then ensure that we align CPD activities with performance and knowledge gaps presented by pharmacists. It is important for employees and employers to devise strategies that will allow the successful incorporation of CPD into daily practice without compromising the pharmacist's responsibility to deliver quality patient services (Bellanger \& Shank, 2010).

The author supports the SAPC's decision of increasing awareness of the CPD recording process for registered pharmacists who are not being tutored through workshops and tutorials. To address the issue of time constraints and travel challenges, CPD activities can be offered online so that they are continuously reviewed and updated. Regular reminders can be sent to pharmacists by the SAPC to improve the uploading of CPD activities online. Increased training and demonstrative videos can be used to address system issues. Strategies and incentives that will encourage employers to promote employee CPD participation should be developed in partnership with the SAPC.

\section{Acknowledgements}

The authors wish to acknowledge all the pharmacists from Mpumalanga Province who participated in the study.

\section{Author contributions}

LG was responsible for the literature review, questionnaire design, data collection process and first draft of the manuscript. EH and SB were responsible for research supervision and review of the manuscript. All authors approved the final version of the manuscript.

\section{References}

Adepu, R., \&Shariff, A. (2010). Development, validation and implementation of continuous professional development programmes for community pharmacists. Indian journal of pharmaceutical sciences, 72(5), 557. https://doi.org/10.4103/0250$474 X .78520$

Alkhateeb, F. M., Attarabeen, O. F., \&Alameddine, S. (2016). Assessment of Texan pharmacists' attitudes, behaviors, and preferences related to continuing pharmacy education. Pharmacy Practice (Granada), 14(3), 00. https://doi.org/10.18549/PharmPract.2016.03.769

Aziz, Z., Jet, C. N., \& Rahman, S. S. A. (2013). Continuing professional development: views and barriers toward participation among Malaysian pharmacists. The European Journal of Social \& Behavioural Sciences, 4(1), 713. https://doi.org/10.15405/FutureAcademy/ejsbs(23012218).2012.4.6

Bellanger, R. A., \& Shank, T. C. (2010). Continuing professional development in Texas: survey of pharmacists' knowledge and attitudes: 2008. Journal of the American Pharmacists Association, 50(3), 368-374. https://doi.org/10.1331/JAPhA.2010.09011

Donyai, P., Herbert, R. Z., Denicolo, P. M., \& Alexander, A. M. (2011). British pharmacy professionals' beliefs and participation in continuing professional development: a review of the literature. International Journal of Pharmacy Practice, 19(5), 290-317. https://doi.org/10.1111/j.20427174.2011.00128.x

FIP policy statement. (2002). Available at: https://www.fip.org/files/fip/WHO/GPP\%20guidelines\%20F IP\%20publication_final.pdf

Gelayee, D. A., Mekonnen, G. B., \&Birarra, M. K. (2018). Involvement of community pharmacists in continuing professional development (CPD): a baseline survey in Gondar, Northwest Ethiopia. Globalization and health, 14(1), 15. https://doi.org/10.1186/s12992-018-0334-0

Grappasonni, I., Tayebati, S. K., Petrelli, F., \&Amenta, F. (2014). The Pharmacist Knowledge and Computer Skills Towards E-health. Results of A Survey Among Italian Community Pharmacists. Journal of Bioinformatics and Diabetes, 1(1), $50 . \quad$ https://doi.org/10.14302/issn.23749431.jbd-13-330

International Pharmaceutical Federation (FIP). (2014). Continuing Professional Development/Continuing Education in Pharmacy: Global Report. The Hague, The Netherlands. https://www.fip.org/file/1407

Kasvosve, I., Ledikwe, J. H., Phumaphi, O., Mpofu, M., Nyangah, R., Motswaledi, M. S., Martin, R., \&Semo, B. W. (2014). Continuing professional development training needs of medical laboratory 
personnel in Botswana. Human resources for health, 12(1), 46. https://doi.org/10.1186/1478-4491-12-46

Kenya Pharmacy and Poisons Board. (2013). CPD among Pharmacy Professionals- Assessment Report on Status of Implementation in Kenya. Available from: http://apps.who.int/medicinedocs/documents/s21952en/s2 1952en.pdf

Kostrzewski, A. J., Dhillon, S., Goodsman, D., \& Taylor, K. M. (2009). The influence of continuing professional development portfolio records on pharmacy practice. International Journal of Pharmacy Practice, 17(2), 107-113. https://doi.org/10.1211/ijpp.17.02.0006

Laaksonen, R., Duggan, C., \& Bates, I. (2009). Overcoming barriers to engagement in continuing professional development in community pharmacy: a longitudinal study. Pharmaceutical Journal, 282(7535), 44-48. https://www.pharmaceuticaljournal.com/download?ac $=1066302$

Marriott, J. L., Duncan, G. J., \& Namara, K. P. M. (2007). Barriers to pharmacist participation in continuing education in Australia. Pharmacy education, 7(1). https://doi.org/10.1080/15602210601084176

McConnell, K. J., Delate, T., \& Newlon, C. L. (2012). Impact of continuing professional development versus traditional continuing pharmacy education on learning behaviors. Journal of the American Pharmacists Association, 52(6), 742-752. https://doi.org/10.1331/JAPhA.2012.11080

Moyo, N.T., \&Renard, C. (2016). Functions of a Professional Association: Module 4. The Professional Association Strengthening Project. Available at: http://www.strongprofassoc.org/wpcontent/uploads/2016/05/PAS-Module-4-May2016.pdf

National Department of Health, South Africa. (2019, June 6). Regulations relating to continuing professional development. Available at: https://www.gpwonline.co.za

Owen, J. A., Skelton, J. B., \& Maine, L. L. (2020). Advancing the Adoption of Continuing Professional Development (CPD) in the United States. Pharmacy, 8, 157.ttps://doi.org/10.3390/pharmacy8030157

Pharmacy Act. (1974). Available at: https://www.sapc.za.org/Media/Default/Documents/CPD\%2 Oregulations\%20-\%20English\%20(003).pdf

Pharmacy Board of Australia. (2015). Guidelines on Continuing Professional Development. Available at http://www.pharmacyboard.gov.au/News/2015-10-30registration-standards.aspx

Power, A., Johnson, B. J., Diack, H. L., McKellar, S., Stewart, D., \& Hudson, S. A. (2008). Scottish pharmacists' views and attitudes towards continuing professional development. Pharmacy World \& Science, 30(1), 136-143. https://doi.org/10.1007/s11096-0079156-5

Rouse, M. J. (2004). Continuing professional development in pharmacy. Journal of Pharmacy Technology, 20(5), 303-306. https://doi.org/10.1177/875512250402000509

Saade, S., Ghazala, F., Farhat, A., \& Hallit, S. (2018). Attitudes towards continuous professional development: a study of pharmacists in Lebanon. Pharmacy Practice (Granada), 16(1). https://doi.org/10.18549/PharmPract.2018.01.1103

South African Pharmacy Council (SAPC). (2019). Intern and tutor manual for the pre-registration experience of pharmacist interns. Available at
https://www.pharmcouncil.co.za/Media/Default/Documents/2019\%2 Olntern\%20and\%20Tutor\%20Manual-1.pdf

South African Pharmacy Council (SAPC). (2018, November 12). Statistics for registered persons and organisations. Available at: https://interns.pharma.mm3.co.za/Statistics

Thompson, W., \&Nissen, L. M. (2013). Australian pharmacists' understanding of their continuing professional development obligations. Journal of Pharmacy Practice and Research, 43(3), 213-217. https://doi.org/10.1002/j.20552335.2013.tb00257.x

Tran, D., Tofade, T., Thakkar, N., \& Rouse, M. (2014). US and international health professions' requirements for continuing professional development. American journal of pharmaceutical education, 78(6), 129. https://doi.org/10.5688/ajpe786129

Wheeler, J. S., \& Chisholm-Burns, M. (2018). The benefit of continuing professional development for continuing pharmacy education. American journal of pharmaceutical education, 82(3), 6461. https://doi.org/10.5688/ajpe6461 